\title{
Capital Social e Ações Conjuntas: um estudo de caso no Arranjo Produtivo de vinhos de altitude catarinense ${ }^{1}$
}

\author{
Gustavo Cristiano Sampaio ${ }^{2}$, Marcos Junior Marini ${ }^{3}$ e Gilson Ditzel Santos ${ }^{4}$
}

Resumo: o objetivo deste trabalho é analisar as relações entre o capital social dos agentes e as ações conjuntas desenvolvidas no Arranjo Produtivo Local de vinhos de altitude catarinense. Esta pesquisa classifica-se como descritiva de caráter exploratório, utilizando-se de dados em abordagem quali e quantitativa, com aplicação de questionários estruturados como instrumento de coleta e técnica de pesquisa de campo usando da entrevista. Os resultados apontam para um bom nível de capital social, com destaque para o ótimo nível de confiança, traduzindo-se em ações conjuntas na rede de agentes. Isso tem gerado um bom nível de envolvimento e efetividade de ações conjuntas, a se destacar a organização de eventos, participação conjunta em feiras e eventos, campanha de marketing, desenvolvimento de produtos e processos e capacitação de recursos humanos. Há um pequeno grupo de agentes que apresenta um capital social forte e um ambiente propício para o aumento desse capital em toda a rede. Porém, a avaliação de reciprocidade e densidade apresenta um terço das possibilidades desta rede, ocasionado principalmente pela distância geográfica de muitos agentes que compõem o APL.

Palavras-chaves: Arranjo Produtivo Local, capital social, ações conjuntas, análise de redes sociais, desenvolvimento regional.

Abstract: The goal of this study is to analyze the relations between the agents' social capital and joint actions developed by the cluster of wine produced at the high altitudes of Santa Catarina State (Brazil). This descriptive and exploratory study uses data from qualitative and quantitative approaches, gathering information from the structured questionnaire and this data gathering was conducted through field research using a interview. The results show a good social capital, highlighting the great level of confidence, which reflects on the joint actions done by the agents. As a result, it has created a nice level of involvement and effectiveness of joint actions, highlighting events

1. Data de submissão: 1o de junho de 2016. Data de aceite: 24 de fevereiro de 2018.

2. Universidade Tecnológica Federal do Paraná. Pato Branco, Paraná, Brasil. E-mail: gu_sampaio@hotmail.com

3. Universidade Tecnológica Federal do Paraná. Pato Branco, Paraná, Brasil. E-mail: marini@utfpr.edu.br

4. Universidade Tecnológica Federal do Paraná. Pato Branco, Paraná, Brasil. E-mail: ditzel@utfpr.edu.br 
organization, joint participation at fairs and events, marketing campaigns, development of products and processes and human resources improvement. There is a small group of agents who show a strong social capital and a proper environment to expand this capital throughout the network. However, the evaluation concerning reciprocity and density represents only one third of the possibilities of this group, and it happens especially because of the geographical distance between the agents who are part of the cluster.

Key-words: Cluster, social capital, joint actions, social networking analysis, regional development.

Classificação JEL: R.

DOI: http://dx.doi.org/10.1590/1234-56781806-94790560404

\section{Introdução}

Frente às grandes mudanças institucionais nas estruturas produtivas, na concorrência internacional e os avanços tecnológicos, os Arranjos Produtivos Locais tornam-se um modelo propício para instalação de ambientes inovadores e propulsores do desenvolvimento regional (MARTINS, 2002; SUZIGAN, 2006; CASSAROTTO FILHO e AMATO NETO, 2007; COSTA, 2010; MARINI et al., 2012). Por essa razão, a partir da década de 1980, as discussões e estudos a respeito dos APLs se intensificaram no Brasil.

Porém, os desdobramentos dessa temática no País como política pública ainda podem ser considerados genéricos e superficiais, porque não atingem os objetivos pretendidos em razão do descuido em relação aos problemas e circunstâncias a serem enfrentados. Isto acontece pelo fato de que os agentes públicos ainda desconhecerem as especificidades deste objeto e de transpor a teoria, ações e políticas para diferentes contextos. A demarcação de ações de políticas públicas que colaboram com o desenvolvimento de arranjos produtivos no Brasil ainda é incipiente, apesar do empenho nos últimos anos. Em função do forte desdobramento para o desenvolvimento regional e enfrentamento do subdesenvolvimento, este assunto assume uma importância significativa e merece investimentos e atenção (COSTA, 2010).

Segundo Marini et al. (2012), um APL apresenta características bem peculiares, dentre elas o capital social, proveniente da relação entre seus agentes, tais como empresas, instituições de ensino, instituições de fomento, agentes públicos, organizações que colaboram para o aperfeiçoamento e desenvolvimento de uma atividade específica. Entendemos que este Capital, constituído de reciprocidade, engajamento e confiança, pode culminar no fortalecimento e crescimento destes arranjos. Um dos principais desafios de uma definição operacional de capital social é, portanto, possibilitar, em estudos de casos concretos, não só detectar sua presença ou ausência, mas também determinar se essa variável de fato levou ou não ao fortalecimento da sociedade civil ou ao aumento da cooperação, da interação e da produtividade econômica. Trata-se, portanto de "definir o capital social, separando analiticamente suas origens de suas características centrais, e estas de seus efeitos" (DURSTON, 2000).

Neste vértice, o capital social é uma construção coletiva, fruto da confiança, reciprocidade, normas e sistemas, de agentes de um território, que contribui para a eficiência coletiva, transformando em ações conjuntas (GRANOVETTER, 1985; COLEMAN, 1988, 1990; PUTNAM, 1993, 1996, 2002, 2005; ABRAMOVAY, 2000; AMATO NETO, 2000; CASAROTTO FILHO e PIRES, 2001; ALBAGLI e MACIEL, 2002; COSTA e COSTA, 2005; AMATO NETO e FUCI AMATO, 2009; TEIXEIRA, 2010; MARINI et al., 2012). Complementarmente, uma vertente do pensamento social contemporâneo denomina a base nos trabalhos de James Coleman (1990) e Robert Putnam (1993, 1996), de capital social, que diz respeito a "características da organização social, como confiança, normas e sistemas, que contribuam para 
aumentar a eficiência da sociedade, facilitando as ações coordenadas" (ABRAMOVAY, 2000).

Sob essa perspectiva, o trabalho tem o objetivo de analisar as relações entre o capital social dos agentes e ações conjuntas desenvolvidas pelo Arranjo Produtivo Local de vinhos de altitude catarinense, colaborando cientificamente na medida em que utiliza metodologia para mensuração e análise da relação do capital social e ações conjuntas em Arranjos Produtivos Locais. Por se tratar de um Arranjo recente, este estudo colabora para analisar a relação do capital social existente e as ações conjuntas, possibilitando trazer algumas análises que sirvam de subsídios para a gestão do APL traçar linhas de condutas para sua melhoria.

Este trabalho está estruturado em cinco capítulos: o primeiro apresenta as questões introdutórias, a justificativa e os objetivos desta pesquisa. O capítulo dois apresenta todo o aporte teórico, que inclui os aspectos dos Arranjos Produtivos Locais, capital social e ações conjuntas. O capítulo três aborda os procedimentos metodológicos, contemplando a classificação da pesquisa e população; variáveis e métodos utilizados para análise dos dados. No quarto capítulo são apresentados os resultados encontrados ao final deste trabalho. Finalmente, as considerações finais são apresentadas no quinto capítulo.

\section{Fundamentação teórica}

\subsection{Arranjos Produtivos Locais}

As grandes mudanças institucionais nas estruturas produtivas, na concorrência internacional, os avanços tecnológicos e a valorização de micro e pequenas empresas contribuíram para o surgimento dos arranjos produtivos locais a partir da década de 1980. (CASAROTTO FILHO e PIRES, 2001; MARINI e SILVA, 2012). Essa nova concepção de aglomeração industrial surgiu a partir do sucesso comercial das empresas instaladas no Vale do Silício nos Estados Unidos, aglomeração de alta tecnologia, e os distritos industriais italianos, chamando mais atenção ainda em decorrência da elevada renda per capita nesses espaços (SANTOS et al., 2004).

Os avanços de tais aglomerados no Brasil ocorreram a partir de meados de 1990, por conta dos modelos elencados acima e trabalhos que apresentaram êxito no exterior. Dessa forma, estes têm sido o pilar central do Ministério de Integração Nacional na Política Nacional de Desenvolvimento Regional no que tange à organização social dos atores regionais e geração de emprego e renda. Logo, tornam-se um importante mecanismo de política econômica no Brasil. Percebe-se, porém, nos estudos brasileiros, inúmeras nomenclaturas para tais aglomerações, tais como Parques Tecnológicos, Arranjos Produtivos Locais, Aglomerações Produtivas, Distritos Industriais, Polos Tecnológicos, Sistemas Produtivos Locais, Clusters, Sistemas Locais de Inovação, dentre outros (COSTA, 2010).

Este modelo surgiu de forma muito intensiva, justamente por trazer uma nova perspectiva para o desenvolvimento regional, que incluía outras variáveis na perspectiva nos modelos de desenvolvimento antes conhecidos:

Em comum, estes estudos enfatizavam a explicação dos fenômenos econômico-territoriais procurando nos fatores endógenos das aglomerações produtivas os condicionantes de seu desenvolvimento, incorporando, portanto, variáveis antes não consideradas nos modelos precedentemente em voga: infraestrutura econômica e sistemas de logística; infraestrutura de ensino e pesquisa; qualificação da mão de obra; estágio tecnológico das empresas locais e capacidade de inovação; fatores culturais, políticos e sociais locais; capital social, capacidade de governança e relação entre os agentes regionais; recursos produtivos locais; capacidade de gerar e controlar localmente a acumulação; e existência de interdependências produtivas tanto intra quanto intersetoriais (COSTA, 2010, p. 18).

Segundo Martins (2002), a contribuição dos Arranjos Produtivos Locais para o desenvolvimento regional está atrelada à iniciativa compartilhada, da inovação e do empreendedorismo comunitário (MARTINS, 2002). Em consoante, Reis e Amato Neto (2012) identificam consenso em vários estudos de que “a promoção de ações conjuntas entre empresas e outras organizações potencializa o ganho de eficiência coletiva que a concentração geográfica de um mesmo setor pode ter" (REIS e AMATO NETO, 2012, p. 1).

Entretanto, o fato de existir um distrito industrial ou aglomerado produtivo numa determinada região 
ou localidade não significa haver de fato um Arranjo Produtivo Local. Marini et al. (2012) concluem que a promoção destes arranjos produtivos necessita da articulação dos diversos atores ou agentes locais, influenciados pelos aspectos sociais, culturais, econômicos, ambientais, espaciais, políticos e institucionais presentes naquele território, para uma busca sinérgica da vantagem competitiva e da eficiência coletiva. Existem características comuns aos Arranjos Produtivos Locais, dentre as quais: são aglomerações empresariais com especialidade produtiva; localizam-se em uma concentração geográfica e setorial; existência de processos interativos entre os agentes que os fazem criar vínculos; procuram eficiência coletiva através da aglomeração produtiva; formam-se principalmente por pequenas e médias empresas; são alicerçados por agentes de; estão imbuídos por práticas de cooperação, que geram inovação e aprendizagem (MARINI et al., 2012).

De forma mais genérica, um APL pode ser entendido como um grupo de agentes "orquestrados" por um grau de institucionalização explícito ou implícito ao aglomerado que buscam como finalidade, harmonia, interação e cooperação, não esquecendo, vale repisar, que estes elementos ocorrem num ambiente competitivo, no qual há sujeitos com distintos graus de poder e com projetos territoriais diversos e muitas vezes antagônicos (COSTA, 2010, p. 127).

Dessa forma, os agentes locais tornam-se protagonistas do território, buscando por meio de práticas cooperativas o desenvolvimento de determinadas atividades produtivas. Campos (2009) acrescenta ainda que as firmas localizadas nestes arranjos têm ainda semelhanças históricas, culturais e sociais que estimulam as interações. Isso atribui aos agentes um sentimento de pertencimento a um determinado território, propício ao fortalecimento do capital social.

\subsubsection{Capital social}

Apesar de os estudos realizados por Putnam terem ganhado maior relevância nos estudos sociais, as primeiras experiências com o capital social foram realizadas nos Estados Unidos entre 1835 e 1840, quando Tocqueville fez comparações entre as regiões com alto e baixo desempenhos de capital social. A conclusão do estudo apontou que as empresas com maior desempenho são aquelas inseridas em regiões com alto capital social. Para Tocqueville (2005, p. 23), “o império moral da maioria fundamenta-se na ideia que há mais luzes e sabedoria em muitos homens reunidos do que num só e no número do que na escolha feita pelos legisladores".

Através dos estudos comparativos entre o norte e sul da Itália, Putnam sintetiza algumas questões relativas ao capital social:

- O Contexto Social e a história condicionam profundamente o desempenho das instituições.

- Quanto mais cívico for o contexto, melhor será o governo. Por esse motivo, diante de uma sociedade civil vigorosa, o governo democrático se fortalece em vez de se enfraquecer.

- A reciprocidade generalizada, isto é, fazer sem obrigação, gera vultoso capital social.

- Para a estabilidade política, para a boa governança e mesmo para o desenvolvimento econômico, o capital social pode ser mais importante até do que o capital físico e humano.

- Criar capital social não será fácil, mas é fundamental para fazer a democracia funcionar (PUTNAM, 1996, p. 191).

Coleman (1988) direciona num sentido similar ao de Putnam, ao estabelecer que o capital social surge em torno do culturalismo, fazendo menção do contexto familiar e nos grupos mais fechados e menores para o cultivo e fomento deste capital:

As ações das pessoas são moldadas, redirecionadas, constrangidas pelo contexto social; normas, confiança interpessoal, redes sociais e da organização social são importantes para o funcionamento não só da sociedade, mas também da economia (COLEMAN, 1988, p. 95).

Neste vértice, Coleman (1988), parte do princípio da naturalidade e das relações de confiança entre os indivíduos na formação do capital social, desvinculado das relações econômicas. A confiabilidade gera uma relação de expectativas e comprometimento na retribuição de ações geradas entre seus membros. Por 
fim, critica a teoria institucional pela falta de percepção dessas relações entre as pessoas na constituição do capital social (COLEMAN, 1988).

Putnam (1996, p. 177) afirma que "o capital social é o conjunto de características da organização social, como confiança, normas e sistemas, que contribuem para aumentar a eficiência da sociedade, facilitando as ações coordenadas". Já Coleman (1988, 1990), em seus estudos, expõe seis formas nas quais o capital social pode apresentar-se: obrigações e expectativas; canais de informação; normas e efetivas sanções; relações de autoridade; organizações apropriáveis; organizações intencionais. Woolcock et al. (2003), ao proporem um método de análise do capital social, dividem-no em seis dimensões: a) Grupos e redes; b) confiança e solidariedade; c) ação coletiva e cooperação; d) informação e comunicação; e) coesão e inclusão social; f) autoridade e capacitação (empowerment) e ação política.

Para os autores da vertente neoinstitucionalista, que se dedica ao desenvolvimento, o capital social só passa a ser interessante se ele for articulado conjuntamente entre sociedade organizada e políticas públicas, sem a necessidade de esperar muito tempo para isso. Neste sentido, Evans (1996), Fox (1996) e Durston (1999) dissertam que o capital social só pode ser concebido desde que haja instituições robustas. Estes estudos incorporam novas perspectivas complementares à visão culturalista (LIMA NETO, 2007).

Muls (2008) também disserta sobre a importância da mobilização entre atores locais e instituições como um mecanismo para atenuar as desigualdades sociais:

A mobilização dos atores locais, a formação de redes entre organismos e instituições locais e uma maior cooperação entre empresas situadas em um mesmo território são instrumentos que têm possibilitado aos territórios novas formas de inserção produtiva e uma atenuação das desigualdades sociais (MULS, 2008, p. 3).

Dessa forma, analisar as relações entre as organizações sociais e políticas públicas tem sido relevante nos estudos em desenvolvimento local e regional. A concepção de capital social se opõe à ideia estabelecida em relação ao comportamento humano na civilização moderna, o de que a sociedade é um "conjunto de indivíduos independentes, cada um agindo para alcançar o objetivo a que chegam independentemente uns dos outros, o funcionamento do sistema social consistindo na combinação destas ações dos indivíduos independentes" (COLEMAN, 1990).

Albagli e Maciel (2002) também citam a presença do capital social na melhoria da qualidade de uma comunidade e aumento de seu poder aquisitivo, bem como para o desenvolvimento regional, por meio da implantação do sistema local de inovação em Mondragon, uma cooperativa de trabalhadores fundada em 1956 no País Basco espanhol. Estes trabalhadores, insatisfeitos em seus empregos, fundaram uma cooperativa para produção de lamparinas e fogões, incentivados por um padre carismático. Montou-se, na sequência, escolas técnicas e centros de pesquisa e, posteriormente, uma universidade. Fundaram-se outras cooperativas e, a partir disso, criaram-se também incubadoras de empresas, que propiciaram a constituição de outras cooperativas interligadas. Criou-se nesse ambiente um complexo e sofisticado ambiente financeiro (ALBAGLI e MACIEL, 2002).

Granovetter $(1985,2000)$ ressalta a ideia de confiança ao afirmar que o capital social pode ser considerado uma das vantagens competitivas das estruturas localizadas e da associação de empresas, uma vez que estimula a adoção de estratégias coletivas e inibe comportamentos oportunistas dos agentes envolvidos, azeitando más condutas. Um dos primeiros aspectos mais encontrados na literatura está relacionado à confiança. Santos (2007) disserta que a confiança é vista como lubrificando a vida social e gerando resultados econômicos: sociedades com elevados graus de confiança tornam-se e permanecem ricas porque são cívicas.

\subsubsection{Ações conjuntas}

As pequenas e médias empresas, de maneira geral, apresentam mais dificuldades para gerenciar toda a sua cadeia de valor diante de duas limitações, principalmente em relação à capacidade produtiva, força de vendas e de sua inovação, o que interfere na competitividade. Uma das maneiras de estas conseguirem sobreviver num mercado de intensidade frente às grandes organizações é estabelecer parcerias ou cooperação entre outras organizações de um mesmo segmento. Neste sentido, as aglomerações produtivas, clusters ou arranjos produtivos locais têm sido uma das alternativas salutares para se obter essa vantagem competi- 
tiva. Porém, as aglomerações não atendem aos anseios exclusivos de pequenas e médias empresas, podem ter variações na composição destes, aliando médias, pequenas e grandes empresas, com sistemas de cooperação variados.

As discussões relativas à externalidades, retornos de escala e o papel das ações conjuntas têm sido objeto de estudos desde o final do século XIX, a partir dos estudos sobre os distritos industriais ingleses. Neste aspecto, Casarotto Filho e Amato Neto (2007) argumentam que os arranjos produtivos rompem as características geradas pelas vantagens competitivas tradicionais, buscando vantagens competitivas dinâmicas, baseadas numa infraestrutura propícia, próximas a centros de pesquisa e desenvolvimento, disponibilidade de recursos humanos qualificados e acesso à logística avançada e de comunicação.

Em consequência das discussões em torno dos arranjos produtivos locais, se intensificaram também as "alianças estratégicas" ou acordos cooperativos, definidos em literatura sobre os movimentos de aproximação entre empresas (AMATO NETO, 2000). Estes acordos buscam integração entre elementos, empresas e indivíduos distintos, na qual a identidade cultural pode ser uma característica de aproximação. Quanto maior for a diferença entre as organizações, maior será o desafio para a mudança organizacional (CASAROTTO FILHO e AMATO NETO, 2007).

A busca por recursos e informações, fontes primárias do crescimento econômico, é motivadora para que haja cooperação entre as agentes, o que envolve não só empresas, mas também outras instituições, sendo elas governamentais ou não (PIORE, 2001). Neste sentido, para haver aumento de produtividade é necessário haver mecanismos de integração. Costa e Costa (2005) dissertam que o produto final da coordenação de esforços em aglomerados de empresas é conseguido em razão da divisão do trabalho entre empresas independentes, especializadas em diferentes fases do ciclo de produção. Piore (2001) sugere que existem agentes sociais capazes de transmitir informações, apontar oportunidades e facilitar o acesso a bens públicos para que as empresas deste arranjo obtenham a inovação necessária para o acompanhamento do mercado, haja vista que, individualmente estas empresas possam superar restrições individuais no alcance de uma situação desejável.

Neste sentido, Sengenberger (1988) afirma que:
Associando-se e cooperando umas com as outras, as pequenas empresas podem aumentar consideravelmente o seu peso político e alcançar alguma capacidade de manobra 'estratégica', a qual normalmente as grandes empresas possuem. Como grupo elas não são mais a quantité négligeable das pequenas firmas isoladas, e elas têm, assim, um poder de barganha mais favorável vis-à-vis o governo e a administração local (SENGENBERGER, 1988, p. 256).

Schmidt (2010), a partir do estudo elaborado no Vale dos Vinhedos, no estado do Rio Grande do Sul, que tem várias ações coletivas, identificou que a rede possibilita a criação de valor para os agentes estabelecidos. O selo de Indicação de Procedência, uma destas ações coletivas, tem impacto positivo sobre a venda de vinhos finos, além de influenciar de forma positiva a venda de vinhos comuns dessas firmas processadoras, o que conduz a um contexto de formação de externalidades dentro da rede.

$\mathrm{Na}$ literatura foi encontrada diversidade nas nomenclaturas utilizadas para ações conjuntas, tais como ações cooperativas, ações coletivas, práticas coletivas e práticas cooperativas. Queiroz (2012) faz análise de algumas ações coletivas em seu trabalho, como realização e participação em feiras, treinamento e capacitação de recursos humanos, compras conjuntas, desenvolvimento conjunto de processos e/ou produtos, distribuição conjunta de produtos, programas institucionais. Essas estão diretamente ligadas ao próprio desenvolvimento de seus atores que nele envolvem-se. Estes passam a determinar seus próprios projetos e ações que deverão desenvolver para a consecução de seus objetivos e o aperfeiçoamento da atividade local.

\subsubsection{Relação do capital social e ações conjuntas}

Considerando-se o capital social fruto das relações sociais de uma comunidade, os agentes passam a ser protagonistas de seu próprio espaço e de suas ações. Nos arranjos produtivos locais, todos os agentes, principalmente os agentes econômicos, ou seja, aqueles que desenvolvem a atividade produtiva, geralmente micro e pequenas empresas, procuram se unir, a fim de obter vantagem competitiva diante das grandes empresas ou 
de seus concorrentes. Dessa forma, buscam fortalecer a atividade, por meio de associações ou cooperativas, buscando realizar ações conjuntas junto aos agentes de apoio (instituições públicas, órgãos governamentais e não governamentais, associações, sindicatos, instituições de ensino e pesquisa). Nessa perspectiva, acredita-se que quanto mais estoque de capital social, maiores as chances de ocorrerem ações em prol do bem comum.

A efetividade de ações conjuntas efetivamente só se realizará se houver um capital social mais denso na rede. Nesse vértice, uma das formas identificadas por Putnam (2002) refere-se ao capital social escasso versus denso. O escasso ocorre ocasionalmente e não resulta numa maior aproximação das pessoas. Capital social denso ocorre quando as relações entre as pessoas se estendem além de encontros ocasionais ou de famílias e se materializam em ações conjuntas.

Dessa forma, o capital social é uma construção coletiva, fruto da confiança, reciprocidade, normas e sistemas de agentes de um território, que contribui para a eficiência coletiva, transformando em ações conjuntas (GRANOVETTER, 1985; COLEMAN, 1988; 1990; PUTNAM, 1993, 1996, 2002, 2005; ABRAMOVAY, 2000; AMATO NETO, 2000; CASAROTTO FILHO e PIRES, 2001; ALBAGLI e MACIEL, 2002; COSTA e COSTA, 2005; AMATO NETO e FUCI AMATO, 2009; TEIXEIRA, 2010; MARINI et al., 2012). Putnam (2006) ainda assegura que o desempenho do governo e outras instituições sociais é fortemente influenciado pelo grau de envolvimento dos cidadãos nos assuntos da comunidade. De acordo com a perspectiva dele, regiões que apresentam fortes tradições de engajamento cívico têm melhores desempenhos de instituições e dos governos locais.

Contextualizando de forma mais ampla a relação do capital social e ações conjuntas em APL, Marini et al. (2012) propõem uma configuração de matriz de interdependência para os arranjos produtivos locais no contexto do desenvolvimento local. Trata-se de uma análise multidimensional de abordagem interdisciplinar, que apresenta sete dimensões territoriais (social, econômica, ambiental, espacial, cultural, política e institucional). Estas influenciam e são influenciadas por este APL. O APL, por sua vez, apresenta os principais componentes internos (política públicas, governança local, capital social, ações conjuntas, externalidades incidentes, eficiência coletiva e vantagem competitiva), a qual se inter-relacionam para o objetivo comum, representado pela busca da eficiência coletiva (Schmitz) ou a vantagem competitiva (Porter). Esta proposta de matriz revela uma necessidade de análise composta por inúmeras variáveis e relacionamentos, numa abordagem multidimensional, sistêmica e integrada (MARINI et al., 2012). A partir desta proposta, este trabalho se propôs a estudar a relação entre ações conjuntas e capital social no Arranjo Produtivo Local de vinhos de altitude catarinense.

\section{Metodologia da pesquisa}

Esta pesquisa classifica-se como descritiva de caráter exploratório, utilizando-se de dados em abordagem quali e quantitativa. Como descreve Gil (2014, p. 28), "as pesquisas deste tipo têm como objetivo primordial a descrição das características de determinada população ou fenômeno ou estabelecimento de relações entre variáveis". A pesquisa qualitativa tem se apresentado como um tipo de pesquisa relevante nos trabalhos em pesquisas sociais, caracterizada em si mesma um campo de investigação, que atravessa disciplinas, campos e temas.

Preliminarmente, na fase exploratória desta pesquisa, foi necessário caracterizar este objeto de estudo, o APL de vinhos de altitude, por meio fontes secundárias com aplicação do método de análise documental. Complementarmente, utilizou-se de fontes primárias com a realização de entrevistas semiestruturadas junto à presidência da Acavitis (Associação Catarinense dos Produtores de Vinhos de Altitude) e membros da diretoria para identificação e definição da população desta pesquisa (vinícolas, entidades, organizações públicas, instituições de ensino). Diante das informações coletadas, a população deste APL, composta por 43 (quarenta e três) agentes, foi dividida em três classes: a governança (ocupada pelo vitivinicultor que exerce a presidência da Acavitis no momento), 16 (dezesseis) vitivinicultores (vinícolas associadas à Acavitis), considerados também como agentes econômicos e 26 (vinte e seis) agentes de apoio (agentes que dão suporte à atividade, bem como prefeitura e agência de desenvolvimento regional correspondente à área de abrangência dos vitivinicultores associados). Do total de agentes, apenas 03 (três) vitivinicultores não responderam a esta pesquisa. 
A partir de um estudo bibliométrico e do aporte teórico deste trabalho foi possível elaborar uma proposição de constructo, contemplando as variáveis de análise da relação entre o capital social entre os agentes e as ações conjuntas realizadas neste APL. O instrumento de coleta utilizado para obtenção das informações foi o questionário estruturado, adaptados e diferente para cada um dos grupos de agentes: vitivinicultores, governança e agentes de apoio. Os questionários continham questões objetivas, outras de múltiplas escolhas e a maioria delas com objetivo avaliativo, a partir de uma escala de likert, de 1 a 10. Nas questões envolvendo a análise de redes sociais, visando calcular a densidade, reciprocidade e centralidade desta rede de agentes, foram utilizadas perguntas com múltiplas escolhas contendo a lista de todos os agentes deste APL.

Assim, a coleta de dados foi realizada por meio de pesquisa de campo usando da técnica de entrevista com os representantes dos agentes deste trabalho no período de 16 a 26 de novembro de 2015, com os proprietários ou gerentes das vinícolas, bem como representantes, gerentes ou responsáveis dos agentes que detêm maior informação a respeito do tema trabalhado nesta pesquisa e ligação com os vitivinicultores. Após a coleta de dados, cinco ferramentas foram utilizadas para a tabulação dos dados: (i) Microsoft Excel 2010 Versão 14.0 (planilha eletrônica); (ii) software IBM® SPSS® Statistics Versão 20.0.0; (iii) software Microsoft Word 2010 Versão 14.0 (editor de textos); (iv) software Ucinet 6 for Windows Versão 6.392; (v) NetDraw 2.119. Com este encaminhamento, o próximo capítulo visa apresentar a análise dos resultados obtidos nesta pesquisa.

\section{Análise e discussões dos resultados}

\subsection{Acavitis e o APL de Vinhos de Altitude Catarinense}

O objeto escolhido para este estudo foi o APL de vinhos de altitude catarinense, que apresenta uma peculiaridade em relação às demais regiões vinícolas do estado. Segundo Rosier (2004); Nunes Júnior et al. (2010), o evento considerado como fator determinante para o início da atividade na região é diretamente ligado aos experimentos da Epagri em parceria com o CNPq (Conselho Nacional de Desenvolvimento Científico e Tecnológico) a partir de 1991. Desde então, as equipes das Estações Experimentais da Epagri, Instituto de Pesquisa de Santa Catarina e outras entidades acompanham os vinhedos nos municípios que apresentam altitudes acima de 900 metros, como Água Doce, Bom Retiro, Campos Novos, Videira, Iomerê, São Joaquim e Tangará. Estes locais, por apresentarem clima ameno, latitude elevada e altitudes acima de 1.000 m são propícios à produção de vinhos diferenciados.

Para fortalecer e fomentar ainda mais esta atividade na serra e região meio-oeste catarinense, alguns empresários fundaram a Acavitis (Associação Catarinense dos Produtores dos Vinhos Finos de Altitude), no dia 06 de novembro de 2005, que tem abrangência estadual. Inicialmente, a associação abrigava 37 associados, distribuídos pelos municípios que compreendem as regiões de São Joaquim (São Joaquim, Urupema, Urubici, Bom Retiro, Painel e Campo Belo do Sul), Campos Novos (Campos Novos e Monte Carlo) e Caçador (Caçador, Água Doce, Salto Veloso, Treze Tílias, Videira e Tangará). Juntos, cultivavam 279 hectares com uvas do tipo vitis viníferas (espécie de videira cultivada para produção de vinho na Europa), em altitude entre 900 e 1.400 metros (ACAVITIS, 2015).

A integração e a organização entre diversas empresas vinícolas e demais agentes de apoio, principalmente a criação de uma associação, fortaleceu ainda mais a atividade nas regiões produtoras de vinhos de altitude, um dos motivos que faz caracterizá-lo como um Arranjo Produtivo Local. Nesse sentido, a atividade tem sido considerada por várias entidades de vitivinicultura de altitude como um Arranjo Produtivo Local, conforme aponta Campos (2009) no relatório de pesquisa "Os arranjos produtivos locais no estado de Santa Catarina: mapeamento, metodologia de identificação e critérios de seleção para políticas de apoio", bem como na bibliografia intitulada Políticas Estaduais para Arranjos Produtivos Locais no Sul, Sudeste e Centro-Oeste do Brasil, elaborada também por meio de cooperação técnica incluindo também Redesist, BNDES, Fepese, UFSC, bem como UFPR, Unisinos, Unicamp, UFU, UFF, UFES, UCDB, UCG. Campos et al. (2010), no anexo I, na página 105, relacionam este APL, com atividade produtiva principal (CNAE 11.12-7), como sendo um dos apoiados por política públicas no estado de Santa Catarina, abrangendo aproximadamente 30 cidades do estado, inclusive aquelas já citadas anteriormente. Adicionalmente, 
atribuem o GTP-APL, EPAGRI e Sebrae-SC responsáveis pelo apoio.

Para fazer parte do quadro de associados, o produtor precisa preencher três requisitos: produzir uvas do tipo Vitis vinifera em Santa Catarina, produzir em altitude acima de 900 metros, a produção máxima não pode exceder a 6 mil litros de vinho por hectare de uva plantada e produzir com rigoroso controle de qualidade, que inclui a proibição da adição de açúcar ao mosto, denominado como processo de chaptalização (ACAVITIS, 2015; LOSSO e PEREIRA, 2010). Hoje, o APL conta com a participação 17 vinícolas, abrangendo as cidades de São Joaquim, Urubici, Urupema, Campo Belo do Sul, Monte Carlo, Videira, Treze Tílias, Caçador e Água Doce, conforme mapa apresentado na Figura 1.

A entidade, a partir de 22 julho de 2015, passou a ser denominada "Vinho de altitude produtores e associados". A governança do APL na atualidade é exercida pelo Sr. Acari Amorim, eleito para o cargo de presidente da Acavitis, exercendo esta atribuição há 02 (dois) anos. Amorim está à frente da Vinícola Quinta da Neve há 16 (dezesseis) anos, sendo uma das pioneiras na cidade de São Joaquim. De acordo com Benetti (2016), os associados têm mais de 500 hectares de uva plantados, produzem anualmente aproximadamente 1,2 milhão de garrafas e apresentam faturamento anual superior a R\$ 150 milhões, gerando mais de 2 mil empregos diretos e indiretos.

\subsection{Relação entre capital social e ações conjuntas}

Com intuito de satisfazer o objetivo geral deste trabalho, que analisa a relação entre o capital social e ações conjuntas do APL de vinhos de altitude catarinense, esta seção apresenta as principais discussões desse escopo. Esta análise inicia-se a partir dos resultados obtidos das variáveis construídas neste trabalho e

Figura 1. Localização do APL de vinhos de altitude catarinense

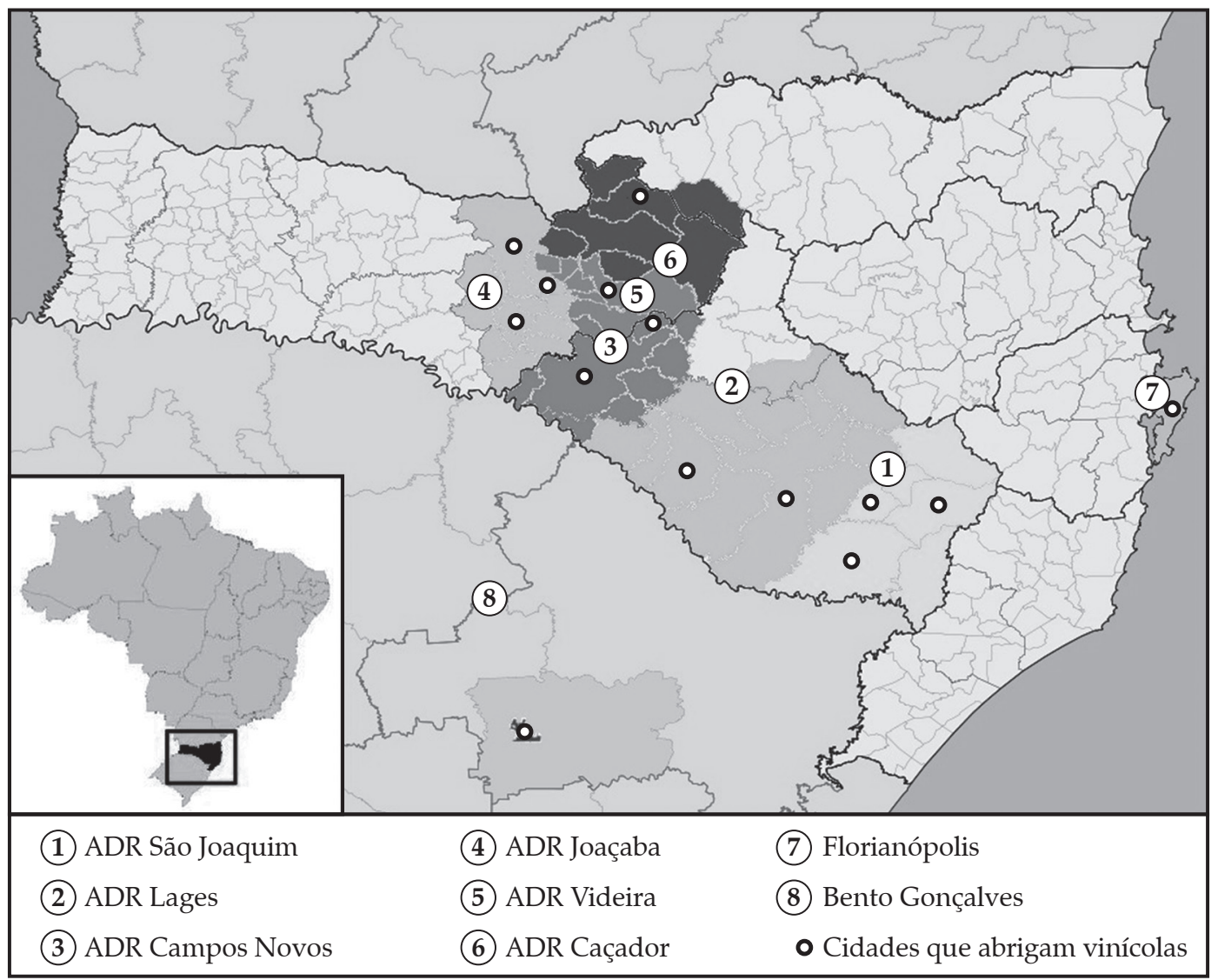

Fonte: Elaborado pelos autores (2016). 
que compõem o binômio estudado, conforme Figura 1. Dessa forma, a síntese dos principais apontamentos é apresentada na Figura 2. Buscando facilitar a compreensão destes números, a avaliação foi escalonada em quatro níveis: baixo $(0,00$ a 2,50$)$, fraco $(2,51$ a 5,00$)$, bom $(5,01$ a 7,50$)$ e ótimo $(7,51$ a 10,0$)$.

A confiança é um dos elementos mais evidentes na literatura quando este está relacionado ao capital social; alguns autores inclusive o tratam como sendo o próprio capital social, ou como o seu principal elemento. Dessa forma, este passa a ser uma variável importante na análise quando o atrelamos a ações conjuntas. No caso estudado, esta foi a variável do capital social que apresentou a maior média geral, correspondente a 7,54. Apesar de este estudo não trazer análises estatísticas mais aprofundadas acerca da relação entre o grau de confiança e ações conjuntas, há uma clara evidência de que os agentes ou grupo de agentes que apresentaram as maiores médias do grau de confiança, tais como Sebrae $(8,72)$, Epagri $(8,63)$, UFSC $(8,13)$ e Embrapa Uva e Vinho $(7,65)$, também são aqueles que efetivamente têm contribuindo proporcionalmente em ações conjuntas.
Na avaliação do de envolvimento e engajamento dos agentes do APL, a média geral apresentada foi de $(6,97)$, resultando numa variável com bom nível de contribuição para o capital social. Como na variável de confiança, há de se ressaltar que o grau de envolvimento e engajamento de alguns agentes, como Sebrae $(8,71)$, Embrapa Uva e Vinho $(8,20)$, Epagri $(8,14)$, a governança do APL $(8,08)$, UFSC $(8,00)$, Santur $(7,64)$ e os vitivinicultores $(7,64)$, se sobressai em relação aos demais.

Portanto, o ótimo índice de confiança e engajamento e envolvimento dos agentes do APL de vinhos de altitude têm contribuído para o aumento da participação e da efetividade das ações conjuntas. Os agentes que apresentam os maiores índices, tanto confiança como envolvimento e engajamento, são aqueles que apresentam maior participação em ações conjuntas, variando entre seis e oito ações conjuntas cada. Evidentemente, o envolvimento e participação dos agentes de apoio ocorrem de acordo com a finalidade e o propósito de cada um. Nesse aspecto, o envolvimento das instituições de pesquisa e educação tem apresentado relevância nas ações conjuntas de desen-

Figura 2. Resultado da análise entre capital social e ações conjuntas

GERA

\begin{tabular}{|c|c|c|c|c|}
\hline \multirow[b]{2}{*}{ Capital social } & \multirow[b]{2}{*}{ Média } & \multirow[b]{2}{*}{ Ações conjuntas } & \multicolumn{2}{|c|}{ Média } \\
\hline & & & $\begin{array}{l}\text { Envol- } \\
\text { vimento }\end{array}$ & $\begin{array}{l}\text { Efeti- } \\
\text { vidade }\end{array}$ \\
\hline Confiança & 7,54 & Compra de insumos e equipamentos & 7,38 & 7,38 \\
\hline Engajamento e comprometimento & 6,96 & Venda conjunta de produtos & 4,67 & 3,33 \\
\hline Troca de informações & 6,53 & Campanha de marketing & 7,47 & 7,53 \\
\hline Normas e sanções & 6,65 & Desenvolvimento de produtos e processos & 7,43 & 7,79 \\
\hline Densidade & 3,95 & Design e estilo de produtos & 6,25 & 6,40 \\
\hline Horizontalidade & 6,22 & Captação de recursos humanos & 6,40 & 6,60 \\
\hline Reciprocidade & 3,69 & Capacitação de recursos humanos & 6,93 & 7,93 \\
\hline Autoridade e capacitação & 7,19 & Obtenção de financiamento & 6,14 & 4,67 \\
\hline \multirow{4}{*}{$\square$ 0,00 a 2,50 - baixo } & & Reivindicações & 7,43 & 6,86 \\
\hline & & Participação conjunta em feiras/eventos & 7,96 & 7,92 \\
\hline & & Organização de eventos & 7,86 & 8,30 \\
\hline & & Enogastroturismo & 7,90 & 7,88 \\
\hline
\end{tabular}

AUMENTAM

Fonte: Elaborada pelos autores (2016). 
volvimento de produtos e processos e na capacitação de recursos humanos, por estarem ligados diretamente ao cultivo, manejo da uva, desenvolvimento de novas variedades, produção e elaboração do vinho e aperfeiçoamento. Os projetos de pesquisa e convênios pactuados, trazendo confiança e obrigações mútuas entre entidades e vitivinicultores, têm propiciado ações conjuntas para a melhoria da atividade na região pesquisada. O Sebrae tem sido apontado também como um ótimo parceiro pelas vinícolas nas questões administrativas, em eventos e projetos específicos para a promoção da vitivinicultura, como a obtenção da Marca Coletiva à Acavitis, em conjunto com Epagri e Embrapa. Entretanto, a participação dos vitivinicultores nestas ações foi razoável. Nas ações que envolvem a compra de insumos e equipamentos, por outro lado, houve participação e envolvimento maiores dos vitivinicultores, visto que alguns agentes contribuíram com esta atividade, como a prefeitura municipal de Videira, o Sebrae, a UFSC e o IFSC, que tem pouco tempo de atividade, mas que está instalando laboratórios experimentais de enologia na cidade de Urupema e é uma das poucas instituições do País que oferece curso superior em Viticultura e Enologia.

Contudo, outras ações abrangem uma parcela significativa de agentes de apoio. Além das instituições citadas acima, como Epagri, UFSC, Sebrae, Embrapa Uva e Vinho, outras entidades têm se envolvido e contribuído para a efetividade de algumas delas. A organização de eventos foi considerada a principal ação e que abrange o maior número de agentes envolvidos, somando quase dois terços do total. Deste total, 16 (dezesseis) são agentes de apoio, incluindo Epagri, Abrasel, Santur, Sebrae, Embrapa Uva e Vinho, UFSC, Unoesc, Sindivinho, uma boa parte das prefeituras e algumas Agências de Desenvolvimento Regional, e 11 (onze) vitivinicultores tiveram participação e envolvimento efetivo. Esta também foi a atividade com a maior média de efetividade, similarmente ao que aconteceu com a ação conjunta participação em feiras e eventos. Ações que envolvem reivindicações, campanha de marketing e a atividade de enogastroturismo também completam a lista de atividades que envolvem a maioria dos agentes citados na atividade de organização de eventos e que têm apresentado bons envolvimento e efetividade. Aliás, ações nesse sentido têm sido um dos principais focos desta atividade, que procura transformar estas regiões produtoras em um espaço de promoção do lazer, da gastronomia e do turismo; portanto, havendo uma necessidade de envolvimento de diversos agentes para fomento de ações, bem como o envolvimento e desenvolvimento de outras atividades, como bares, restaurantes, hotéis e pousadas, além dos altos investimentos em infraestrutura das vinícolas, urbano e logístico nestas cidades. Um dos exemplos típicos do fortalecimento destas ações é a realização das Vindimas de Altitude, realizada em março, período de colheita das uvas. Este evento está na terceira edição e no ano de 2015 ocorreu durante 24 dias, período em que as vinícolas ofereceram passeio enogastronômico com visitas guiadas, almoços e jantares harmonizados, eventos ao pôr do sol e atividades culturais.

Apesar de apresentar médias de confiança e engajamento abaixo do apresentado dos citados anteriormente, a participação e contribuição para a efetividade das ações conjuntas dos demais agentes têm sido proporcional a estas avaliações. Aqueles que apresentam médias baixas de confiança e engajamento e envolvimento, ou que não têm proximidade com o grupo de agentes, são aqueles que também apresentam menor participação e baixa contribuição para a efetividade de ações conjuntas do APL. Esta constatação vem ao encontro com Putnam (1996), que relata que as experiências de mobilização e atuação coletiva acumulam um capital social derivado dos laços de confiança mútua entre os cidadãos, que intensifica o engajamento cívico coletivo.

O tempo de atividade vinícola dos vitivinicultores e a participação dos agentes do APL também são bons indicativos do fortalecimento do capital social. Do total de vitivinicultores, mais de $60 \%$ tem tempo de atividade entre 9 e 16 anos e quase 50\% destes têm uma participação no APL deste a fundação da Acavitis, e 38,5\% participam de 5 a 8 anos, resultando numa média de mais de 7 anos. Em relação ao total de agentes de apoio, 80,76\% declararam participar do APL e a média de participação deste grupo é maior que 7 anos, igualmente ao tempo médio dos vitivinicultores. Além disso, mais da metade, aproximadamente $60 \%$, participam de 9 a 10 anos. Isso denota iniciativa de participação, engajamento e mobilização deste grupo na busca de melhoria da atividade na região. Desta forma, se destaca como uma das principais atividades na maioria dos municípios onde esta está presente, considerando também que na cidade sede da entidade (Acavitis), São Joaquim, ainda não há uma associação empresarial que 
represente e defenda os interesses dos empresários da cidade.

Em relação à participação dos agentes em reuniões formais do APL, dentre os agentes de apoio, 53,33\% dos convocados (15) declaram ter participado de mais de $50 \%$ das reuniões. Já dentre os vitivinicultores respondentes (13), esse percentual é de 46,15. Nazzari et al. (2006), ao ressaltarem a dificuldade em encontrar na literatura um consenso para o capital social, consideram que uma das características principais é a predisposição em participar de atividade cooperativa e associativas, e este elemento é considerado importante para o desenvolvimento do cooperativismo.

Portanto, a análise das duas variáveis do capital social, bem como o tempo de atividade e participação no APL, aponta para um bom nível de confiança e engajamento e comprometimento entre os agentes que apresentam um bom nível de engajamento e efetividade na maioria das ações conjuntas organizadas pelo grupo de agentes do APL. Porém, esta média se eleva em razão dos valores de alguns agentes, o que tem possibilitado ações conjuntas relativamente significativas ao grupo de agentes da rede. Esta análise ressalta a ideia de que a confiança e engajamento, frutos do capital social, podem ser considerada uma das vantagens competitivas das estruturas localizadas e da associação de empresas, uma vez que estimula a adoção de estratégias coletivas e inibe comportamentos oportunistas dos agentes envolvidos, azeitando más condutas (GRANOVETTER, 1985, 2000; COLEMAN, 1988, 1990; PUTNAM, 1993, 1996, 2002, 2005). Neste vértice, a análise realizada baliza-se na afirmação de que o capital social é uma construção coletiva, fruto da confiança, reciprocidade, normas e sistemas, de agentes de um território, a qual contribui para a eficiência coletiva, transformando em ações conjuntas (GRANOVETTER, 1985; COLEMAN, 1988, 1990; PUTNAM, 1993, 1996, 2002, 2005; ABRAMOVAY, 2000; AMATO NETO, 2000; CASAROTTO FILHO e PIRES, 2001; ALBAGLI e MACIEL, 2002; COSTA e COSTA, 2005; AMATO NETO e FUCI AMATO, 2009; TEIXEIRA, 2010; MARINI et al., 2012).

A troca de informações é também um elemento muito importante para o fortalecimento do capital social da rede de agentes de um APL. A média geral dessa variável apresentou-se boa numa escala de 1 a 10, resultando em 6,53. A análise da capacidade do APL em disseminar informações entre os vitivinicultores foi
6,62, enquanto que a avaliação da capacidade dos vitivinicultores em receber informações dos agentes de apoio foi 6,54. Já a avaliação dos agentes de apoio em relação ao recebimento de informações sobre a condução do APL foi 5,81. Além disso, a qualidade e a utilidade das informações disseminadas no APL foram avaliadas em 7,32. Ao aferir a periodicidade de troca de informações entre os agentes, há algum tipo de contato entre $62,31 \%$ das relações possíveis dentro do APL. Os agentes que têm uma interação maior com a rede (Sebrae, Epagri, Governança e UFSC) são aqueles que apresentam maior participação em ações conjuntas deste APL.

A governança do APL é evidenciada neste trabalho como uma grande articuladora entre os agentes de apoio. O contato semanal ocorre com aproximadamente dois terços destes $(57,15 \%)$; portanto, tem uma interação muito grande com o grupo de agentes de apoio e vitivinicultores, servindo de intermediação entre os dois grupos. Consequentemente, um bom nível de troca de informações reflete no envolvimento e na efetividade dos agentes nas atividades conjuntas, haja visto que existe um núcleo de agentes que têm uma interatividade muito grande. Gnyawali e Madhavan (2001) dissertam que vínculos internos intensos facilitam o fluxo de informações, ou seja, reduzem a necessidade de cada pessoa, individualmente, acessar uma fonte primária de dados, podendo basear-se na transmissão de informações que ocorre dentro do grupo, uma vez que estas são de caráter refinado e confiável.

Em relação a normas e sanções do APL de vinhos de altitude, a média final apresentada foi de 6,65. Logo, esta variável do capital social também apresenta um bom resultado. Os resultados mais detalhados evidenciam que há uma cobrança maior dos agentes de apoio do que os vitivinicultores. Coleman (1988) afirma "que normas e sanções constituem capital social onde elas encorajam os indivíduos a trabalharem por um bem comum, abandonando interesses próprios imediatos." Costa e Costa (2005) destacam que, quando os agentes compartilham normas, reduzem a incerteza, pois permitem aos atores prever o comportamento mútuo. Verschoore e Balestrim (2008) enfatizam que o empreendimento de ações colaborativas complexas entre empresas se torna possível através do capital social, uma vez que a formação de uma rede de cooperação será influenciada pelo grau com que as pessoas de uma comunidade empresarial compartilham normas e valo- 
res e são capazes de subordinar os interesses individuais aos coletivos.

A densidade $(0,3950)$ e reciprocidade $(0,3689)$ indicam que a rede apresenta aproximadamente um terço das possibilidades de interação para esta rede de agentes. O resultado dessas duas variáveis é avaliado como baixo, considerando que os valores destas análises variam de 0 a 1 . Porém, há uma interação maior de um pequeno grupo de agentes de apoio e vitivinicultores, principalmente aqueles localizados na região onde se situa a sede da governança do APL. Neste vértice, é possível considerar que a disposição geográfica dessa rede interfere nestas relações. A região de São Joaquim (onde se situa a sede da governança deste APL), tem 22 (vinte dois) agentes e 13 (treze) vitivinicultores, sendo que somente dois estão fora da cidade mencionada. Há uma distância bastante considerável entre esta região e o outro núcleo, compreendido pelas cidades de Videira, Treze Tílias, Monte Carlo, Caçador e Água Doce. Este segundo, na qual possui Videira como cidade central, em razão da Estação Experimental da Epagri, está a 269 quilômetros da cidade sede do APL. Este segundo núcleo é composto por 16 (dezesseis) agentes de apoio e somente 4 (quatro) vitivinicultores. Portanto, trata-se de um núcleo um pouco disperso localmente considerando o raio de distância entre ela e a cidade de Videira.

Percebe-se, dessa forma, que alguns agentes de apoio como Agências de Desenvolvimento Regional e algumas prefeituras municipais apresentam pouca ou nenhuma interação com o APL, como as prefeituras de Monte Carlo, de Caçador, de Urupema, as Agências de Desenvolvimento Regional de Caçador, Campos Novos, Joaçaba e Lages. Agentes como Abrasel e Fiesc possuem relativa participação em razão da sua finalidade e atribuição junto a este Arranjo Produtivo Local, na qual têm papel de articuladores e não de executores propriamente dito. Apesar disso, a reciprocidade e densidade têm possibilitado a organização de algumas ações conjuntas nesse arranjo por possuir um núcleo forte e articulado, haja vista os resultados apresentados nas demais variáveis já apresentadas.

A grande maioria das vinícolas e os agentes Sebrae, Santur, Agência de Desenvolvimento Regional de São Joaquim, prefeitura municipal de São Joaquim, Embrapa Uva e Vinho, Epagri, UFSC, Udesc e IFSC (apesar de ser recente) são os que têm maior reciprocidade e densidade na rede de agentes do APL de vinhos de altitude. Analisando-se individualmente, são os agentes que apresentam maior envolvimento e contribuição efetiva para a realização das ações conjuntas desenvolvidas pelo grupo de agentes. Dessa forma, as ações que apresentam maiores médias de envolvimento e efetividade são: campanha de marketing, desenvolvimento de produtos e processos, capacitação de recursos humanos, participação conjunta de feitas e eventos, organização de eventos e o enogastroturismo.

O percentual de centralidade da rede apresentado foi de $45,125 \%$. Os nós mais centrais desta rede são a governança do APL, Sebrae e Epagri, que têm 29 (vinte e nove) apontamentos cada; individualmente, cada um apresenta $69,05 \%$ dos laços totais possíveis. Complementarmente a essa avaliação, a maioria dos agentes indicou que a tomada de decisão e participação nas decisões no APL são tomadas conjuntamente (50,05\% das respostas). O APL possui uma capacidade de articulação de 7,25 e o sucesso obtido por meio das reivindicações foi de 7,41. Esses dados demonstram um bom nível de capital social, que reflete ações conjuntas de interesse comum a uma grande parte dos agentes deste APL $(7,18)$ e há uma boa parte das demandas provenientes dos agentes que são concretizadas em ações conjuntas $(7,03)$. Neste sentido, Putnam (1996) ressalta que a multiplicação das relações de confiança provoca o fortalecimento de seus componentes horizontais e, ao mesmo tempo, o enfraquecimento de suas redes verticais e, que o associativismo horizontal, fruto de confiança, normas e redes de solidariedade produziria relações cívicas virtuosas, ao passo que a verticalidade causa a obstrução da ação coletiva. Acrescenta ainda que sociedades baseadas no associativismo horizontal têm um grau elevado de engajamento cívico e auto-organização superior às sociedades verticalizadas. Além de terem um elevado desempenho econômico, as horizontalizadas conseguem garantir o bem-estar social de seus cidadãos (PUTNAM, 1996).

Igualmente, o reflexo direto do capital social em ações conjuntas também é conferido quando analisamos o grau de autoridade e capacitação (empoderamento), que apresentou média de 7,19 quando confrontado com as questões que analisam a avaliação das demandas e interesse comum das ações conjuntas, com médias de 7,18 e 7,03, conforme Tabela 1 . Considerando que a maioria dos agentes entende que a forma de participação no APL acontece de forma democrática e voluntária e que há um bom grau de 
Tabela 1. Resumo da análise das ações conjuntas realizadas nos últimos 05 (cinco) anos de existência do APL

\begin{tabular}{llc}
\hline \multicolumn{1}{c}{ Ações conjuntas } & N (\%) & Média \\
\hline Envolvimento dos agentes nas ações conjuntas desenvolvidas pelo APL & 37,39 & 6,98 \\
Avaliação das ações conjuntas realizadas pelo APL & 36,32 & 6,88 \\
Resultados e ganhos competitivos obtidos com as ações conjuntas & 72,31 & 5,80 \\
As ações conjuntas refletem o interesse comum de todos os agentes do APL & 84,62 & 7,18 \\
Demandas sugeridas refletem em ações conjuntas & 76,92 & 7,03 \\
Média geral & & 6,77 \\
\hline
\end{tabular}

Fonte: Elaborada pelos autores (2016).

articulação e de sucesso nas reivindicações realizadas por este grupo, estas questões têm resultado em ações conjuntas que atendem ao interesse comum e que as demandas sugeridas pela maioria dos agentes têm gerado ações conjuntas.

Os resultados e ganhos competitivos gerados pelas ações conjuntas são provas de que o capital social é um elemento muito presente no APL de vinhos de altitude, pois a média geral desta avaliação é considerada boa, com possibilidade de aumentar ainda mais estes resultados. Portanto, a pesquisa aponta para a existência de um capital social "bom" para um pequeno grupo de agentes de apoio e vitivinicultores, principalmente àqueles organizados em torno da sede da governança do APL, e que tem possibilitado muitas ações conjuntas para o fortalecimento da atividade na região pesquisada. Um dos grandes desafios apresentados, como mostra a análise de reciprocidade e densidade da rede, é possibilitar a proximidade maior entre os dois grandes núcleos formados nas regiões do planalto e meio-oeste catarinense e buscar unir interesses comuns para o fortalecimento da atividade de vinhos de altitude.

\section{Considerações finais}

Os trabalhos de pesquisa realizados pela Epagri e, sequencialmente, UFSC e Embrapa, apresentam-se como um fator propulsor para os investimentos iniciais nesta atividade. Apostando num segmento de mercado vitivinicultor incipiente no Brasil, de fortes investimentos financeiros e de retornos mais longos, empresários consolidados em outros segmentos e profissionais liberais, apostam em produtos diferenciados dentro da vitivinicultura. No entanto, ressalta-se que é um ramo de bastante competitividade, principalmente frente aos produtos nacionais e importados mais con- solidados. Este APL, aliado às características já destacadas, busca o fortalecimento da atividade vinícola de altitude por meio do associativismo e da cooperação entre os diversos agentes desta região. Neste sentido, este trabalho debruçou-se a analisar as relações entre o capital social e ações conjuntas desenvolvidas pelos agentes do Arranjo Produtivo Local de vinhos de altitude catarinense.

O ótimo índice de confiança e o bom nível engajamento e envolvimento dos agentes do APL de vinhos de altitude têm contribuído para o aumento da participação e da efetividade das ações conjuntas. Os agentes que apresentam as maiores médias, tanto confiança como envolvimento e engajamento, são aqueles que têm maior participação em ações conjuntas. O envolvimento das instituições de pesquisa e educação tem apresentado relevância nas ações conjuntas de desenvolvimento de produtos e processos e na capacitação de recursos humanos, por estarem ligados diretamente ao cultivo, manejo da uva, desenvolvimento de novas variedades, produção e elaboração do vinho e aperfeiçoamento. Os projetos de pesquisa e convênios pactuados, trazendo confiança e obrigações mútuas entre entidades e vitivinicultores, têm propiciado ações conjuntas para melhoria da atividade na região pesquisada. O Sebrae tem sido apontado também como um ótimo parceiro pelas vinícolas nas questões administrativas, em eventos e projetos específicos para a promoção da vitivinicultura, como por exemplo, a obtenção da Marca Coletiva à Acavitis, em conjunto com Epagri e Embrapa.

A governança do APL é evidenciada neste trabalho como uma grande articuladora entre os agentes de apoio. O contato semanal ocorre com aproximadamente dois terços destes $(57,15 \%)$; portanto, possui uma interação muito grande com o grupo de agentes de apoio e vitivinicultores, servindo de intermedia- 
ção entre os dois grupos. Consequentemente, um bom nível de troca de informações reflete no envolvimento e efetividade dos agentes nas atividades conjuntas, haja vista que existe um núcleo de agentes que têm uma interatividade muito grande.

Entretanto, a densidade $(0,3950)$ e reciprocidade $(0,3689)$ indicam que a rede apresenta aproximadamente um terço das possibilidades de interação para esta rede de agentes. O resultado dessas duas variáveis é avaliado como baixo, considerando que os valores destas análises variam de 0 a 1 . Outrossim, há interação maior de um pequeno grupo de agentes de apoio e vitivinicultores, principalmente aqueles localizados na região que situa-se a sede da governança do APL. Neste vértice, é possível considerar que a disposição geográfica dessa rede interfere nestas relações. O percentual de centralidade da rede apresentado foi de 45,125. Os nós mais centrais mais centrais desta rede são a governança do APL, Sebrae e Epagri, que possuem 29 (vinte e nove) apontamentos cada, individualmente cada um apresenta $69,05 \%$ dos laços totais possíveis.

Esta pesquisa contribui para o conhecimento científico na medida em que propõe um constructo para mensuração do capital social e ações conjuntas em Arranjos Produtivos Locais e a análise de suas relações. Por outro lado, os dados aqui apresentados servirão de análise para o Arranjo Produtivo de vinhos de altitude na busca de avaliar os aspectos positivos das relações estabelecidas entre os agentes e buscar melhorias em aspectos que possam aumentar o capital social entre estes agentes na busca de fortalecimento do APL e da atividade vinícola de altitude como um todo.

A limitação deste trabalho centra-se na análise momentânea dos elementos do capital social e das ações conjuntas. Em razão do tempo e da quantidade de questionários aplicados, as questões que compõem os questionários deste estudo não possibilitam trazer elementos qualitativos e históricos ocorridos no Arranjo Produtivo Local que oportunizassem um aprofundamento maior da análise qualitativa do binômio capital social e ações conjuntas. Outra limitação do estudo, em razão da abrangência locacional deste arranjo, foi a identificação inicial de todos os agentes envolvidos e dos entrevistados que representassem adequadamente cada um dos agentes de apoio selecionados na pesquisa, bem como a dificuldade para entrevistar todos os agentes deste APL durante o tempo proposto.
Para estudos futuros, sugere-se repetir esta análise no mesmo Arranjo Produtivo Local, em um período de tempo, buscando traçar um comparativo frente aos dados coletados nesta pesquisa, além de expandir este mesmo constructo em outros APLs semelhantes, para se obter dados comparativos e identificar melhorias no instrumento de coleta.

\section{Referências}

ABRAMOVAY, R. O capital social dos territórios: repensando o desenvolvimento rural Economia Aplicada - volume 4, n², abr.jun. 2000.

ACAVITIS. Associação catarinense dos produtores de vinhos finos de altitude. Disponível em: <www.acavitis.com. br>. Acesso em: ago. 2015.

ALBAGLI, S. e MACIEL, M. L. Capital social e empreendedorismo local. In: Proposição de Politicas para a promoção de Sistemas Produtivos Locais de Micro e Pequenas Empresas. Redes de Sistemas Produtivos Inovativos Locais. UFRJ, 2002.

AMATO NETO, J. Rede de cooperação produtiva e clusters regionais. São Paulo: Ed. Atlas, 2000. 164 p.

e FUCCI AMATO, R. C. Capital social: contribuições e perspectivas teórico-metodológicas para análise de redes de cooperação produtiva e aglomerações de empresas. Revista Gestão Industrial, Ponta Grossa, v. 5. n. 1, p. 18-42, 2009.

BENETTI, E. Rota dos vinhos de altitude levam riqueza para a Serra de SC. Diário Catarinense, Florianópolis, SC, 14 mar. 2016. Disponível em: <http://dc.clicrbs. com.br/sc/colunistas/estela-benetti/noticia/2016/03/ rotas-dos-vinhos-de-altitude-levam-riqueza-para-aserra-de-sc-5110895.html>. Acesso em: 24 abr. 2016.

BORGATTI, S. P. NetDraw: Network Visualization. Analytic Technologies: Harvard, MA, 2002.

., EVERETT, M. G. e FREEMAN, L. C. Ucinet for Windows: Software for Social Network Analysis. Harvard, MA: Analytic Technologies, 2002.

CAMPOS, A. C. Estrutura de governança: o caso do Arranjo Produtivo Local (APL) do setor de confecção de Maringá (PR). Textos de Economia, Florianópolis, v. 12, n. 1, p. 134-155, jan./jun. 2009.

CAMPOS, R. R. (Coord.). Os arranjos produtivos locais no Estado de Santa Catarina: Mapeamento, metodologia de identificação e critérios de seleção para políticas de apoio. Primeiro Relatório da Pesquisa 
"Análise do Mapeamento e das Políticas para Arranjo Produtivos Locais no Sul, Sudeste e Centro-Oeste do Brasil". Florianópolis: UFSC, 2009. 59p. (Contrato Fepese-BNDES.)

. et al. (Orgs.) Políticas estaduais para arranjos produtivos locais no Sul, Sudeste e Centro-Oeste do Brasil. Rio de Janeiro: E-papers, 2010.

CASAROTTO FILHO, N. e AMATO NETO, J. Cooperação entre pequenas empresas, garantia mutualista e desenvolvimento regional: reflexões sobre sistemas de garantia de crédito. REAd - Revista Eletrônica de Administração, Ed. 57, v. 13, n. 3, set./dez. 2007.

CASAROTTO FILHO, N. e PIRES, L. H. Redes de pequenas e médias empresas e desenvolvimento local. São Paulo: Atlas, 2001

COLEMAN, J. S. Social Capital in the Creation of Human Capital. The American Journal of Sociology, Vol. 94, Supplement: Organizations and Institutions: Sociological and Economic Approaches to the Analysis of Social Structure. p. S95- S120, 1988.

Foundations of social theory. Cambridge, Mass. London: The Belkness Press of Har-vard University Press, 1990.

COSTA, A. B. e COSTA, B. M. Cooperação e capital social em arranjos produtivos locais. Trabalho apresentado no XXXIII Encontro Nacional de Economia, 6 a 9 de dezembro de 2005. Disponível em: <http://www. anpec.org.br/encontro2005/artigos/A05A113.pdf > . Acesso em: 26 mar. 2015.

COSTA, E. J. M. Arranjos Produtivos Locais, Políticas Públicas e Desenvolvimento Regional. Ministério da Integração Nacional - Governo do Estado do Pará IDESP. Brasília: Mais Gráfica Editora, 2010.

DURSTON, J. Construyendo Capital Social Comunitario. Revista de la CEPAL, n. 69, p. 103-118, dez. 1999.

Qué es el capital social comunitario? Santiago de Chile: CEPAL, 2000. (Serie Políticas Sociales, 38)

EVANS, P. Government action, social capital and development: reviewing the evidence on synergy, Revista World Development, v. 24, n. 6, p. 1119-1132, 1996.

FOX, J. How does a civil society thicken? The political construction of social capital in rural México. World Development, v. 24, n. 6, p. 1089-1103, 1996.

GIL, A. C. Métodos e técnicas de pesquisa social. 6. ed. São Paulo: Atlas, 2014.
GNYAWALI, D. R. e MADHAVAN, R. Cooperative networks and competitive dynamics: a structural embeddedness perspective. Academy of Management. The Academy of Management Review, v. 26, n. 3, jul. 2001.

GRANOVETTER, M. Economic action and social structure: the problem of embeddedness. American Journal of Sociology, v. 91, n. 3, p. 481-510, 1985.

GRANOVETER, M. S. et al. Social networks in Silicon Valley. In: LEE, C. M. et al. (Eds.). The Silicon Valley edge. Stanford University Press, 2000. p. 217-247.

LIMA NETO, E. J. A noção de capital social e seu lugar na pauta de agências de desenvolvimento. Revista Ideas, v. 1, n. 1, p. 44-59, jun./dez. 2007.

LOSSO, F. B. e PEREIRA, R. M. F. A. O turismo e a produção de vinhos finos na região de São Joaquim (SC): notas preliminares. Anais do VI Seminário de Pesquisa em Turismo do MERCOSUL - saberes e fazeres no turismo: Interfaces. Jul. 2010.

MARINI, M. J. e SILVA, C. L. S. Desenvolvimento Regional e Arranjos Produtivos Locais: uma abordagem sob a ótica interdisciplinar. Revista Brasileira de Gestão e Desenvolvimento Regional, GEDR, v. 8, n. 2, p. 107-129, mai-ago/2012, Taubaté, SP, Brasil.

MARINI, M. J. et al. Avaliação da contribuição de Arranjos Produtivos Locais para o desenvolvimento local. Revista Bibliográfica de Geografía y Ciencias Sociales, v. 17, n. 996, 2012.

MARTINS, S. R. O. Desenvolvimento local: questões conceituais e metodológicas. Revista Internacional de Desenvolvimento Local, v. 3, n. 5, set. 2002.

MULS, L. M. Desenvolvimento local, espaço e território: o conceito de capital social e a importância da formação de redes entre os organismos e instituições locais. Economia, v. 9, n. 1, jan./abr. 2008.

NUNES JÚNIOR, C. L. et al. Análise do APL de vinhos de Altitude do Planalto Catarinense. VI Encontro de estudos sobre empreendedorismo e gestão de pequenas empresas. Recife (PE), abr. 2010.

PIORE, M. The emergenceroel of social intermediares in the new economy. Annal of Public and Cooperative Economics, v. 72, n. 3, p. 339-350, 2001.

PUTNAM, R. 'The prosperous community: social capital and public life' in the American Prospect, 4:13, 1993.

1996.

. Comunidade e democracia. Rio de Janeiro: FGV,

. Democracies in flux: the evolution of social capital in contemporany society. New York: Oxford University Press, 2002. 
. Comunidade e democracia: a experiência da Itália moderna. Rio de Janeiro, FGV, $4^{\mathrm{a}}$ ed., 2005.

Comunidade e democracia: a experiência da Italia Moderna. 5. ed. Rio de Janeiro: Editora FGV, 2006.

QUEIROZ, T. R. Esboço de uma rede de cooperação em um Arranjo Produtivo Local na Indústria Calçadista Paulista, 2012. Tese - Programa de Pós-graduação em Engenharia de Produção, 2012.

REIS, A. P. e AMATO NETO, J. Aprendizagem por cooperação em rede: práticas de conhecimento em arranjos produtivos locais de software. Produção, v. 22, n. 3, p. 345-355, maio/ago. 2012. Disponível em: < http:// dx.doi.org/10.1590/S0103-65132012005000023>. Acesso em: 03 fev. 2015.

ROSIER, J. P. Novas regiões: vinhos de altitude no sul do Brasil. In: X Congresso Brasileiro de Viticultura e Enologia, 2004.

SANTOS, G. A. G., DINIZ, E. J. e BARBOSA, E. K. Aglomerações, arranjos produtivos locais e vantagens competitivas locacionais. Revista do BNDES, Rio de Janeiro, v. 11, n. 22, p. 151-179, dez. 2004.

SANTOS, V. B. Capital Social em áreas de Arcordos de Pesca na Amazônia Oriental: articulações entre escalas e aspectos institucionais e organizativos nos processos de aprendizagem e inovações de pescadores artesanais ribeirinhos. Anais do II Seminário Nacional Movimentos Sociais, Participação e Democracia. UFSC, Florianópolis, 2007.
SCMIDT, C. M. Criação e apropriação de valor no sistema agroindutstrial do vinho do Vale dos Vinhedos, 2010. Tese (Doutorado) - Programa de Pós-graduação em Administração, Universidade de São Paulo, 2010.

SENGENBERGER, W. Economic and social perspectives of small enterprises. Labour and Society, v. 13, n. 3, 1988.

SUZIGAN, W. (Coord.). Identificação, mapeamento $e$ caracterização estrutural de arranjos produtivos locais no Brasil. Relatório Consolidado, IPEA-DISET, out. 2006.

TEIXEIRA, A. F. Capital social em um Arranjo Produtivo Local: estudo da indústria têxtil e de confecção do município de americana e região, 2010. Dissertação (Mestrado em Administração) - Pontifícia Universidade Católica de São Paulo, São Paulo, 2010.

TOCQUEVILLE, A. A democracia na América: leis e costumes de certas leis e certos costumes políticos que foram naturalmente sugeridos aos americanos por seu estado social democrático. 2. ed. São Paulo: Martins Fontes, 2005.

VERSCHOORE, J. R. e BALESTRIN, A. Fatores relevantes para o estabelecimento de redes de cooperação entre empresas do Rio Grande do Sul. RAC, Curitiba, v. 12, n. 4, p. 1043-1069, out./dez. 2008.

WOOLCOCK, S. European Trade Policy: Global Pressures and Domestic Constraints. In: WALLACE, H. e WALLACE, W. (Orgs.). Policy-Making in the European Union. 4. ed. Oxford: Oxford University Press, 2000, p. 373-400.

Todo o conteúdo deste periódico, exceto onde estiver identificado, está licenciado sob uma Licença Creative Commons (cc by 4.0). 
